\title{
MICRONUTRIENTES NA COPA E SUAS CORRELAÇÕES COM O CRESCIMENTO DA ARAUCARIA ANGUSTIFOLIA (BERTOL.) O. KTZE PLANTADA EM PASSO FUNDO, RS
}

\author{
Micronutrients on the crown and its correlation with the growth \\ of Araucaria angustifolia (Bertol.) O. kuntze, planted in Passo \\ Fundo, Rio Grande do Sul
}

\author{
Juarez Martins Hoppe * \\ Marcos Vinicius Winckler Caldeira ${ }^{* *}$
}

\section{Resumo}

O presente trabalho foi realizado em povoamentos de Araucaria angustifolia, aos 29 anos de idade, plantados na Floresta Nacional de Passo Fundo, RS (FLONA/Passo Fundo, RS). Os objetivos foram: analisar a concentração dos nutrientes na copa, bem como correlacionar os parâmetros de crescimento com a concentração dos nutrientes nas folhas de $A$. angustifolia. Para o presente estudo, foram utilizados dois talhões com 4,4 e 6,8 ha, respectivamente. Em cada talhão foram selecionados quatro sítios, com diferentes crescimentos, baseado na altura dominante do povoamento. Por meio do diâmetro médio de cada sítio, foram selecionadas quatro árvores por sítio, com altura similar à altura dominante do local. Nas quatro árvores selecionadas, em cada verticilo, na orientação norte, foram coletadas folhas do último período de crescimento para análise nutricional. Para fazer a correlação da concentração dos nutrientes nas folhas, foram utilizados os seguintes parâmetros de crescimento: altura total; incremento periódico anual nos últimos cinco anos (IPA, 24-25) e o incremento corrente anual do último ano (ICA). As maiores concentrações de B foram observadas nos verticilos superiores, porém, as maiores concentrações de Mn e Zn nos verticilos inferiores. Foi observado que o aumento nas concentrações de $\mathrm{Cu}$ e $\mathrm{B}$, nas folhas, está associado às maiores alturas das árvores. As melhores correlações são apresentadas pelas concentrações de $\mathrm{Cu}$ e B nas folhas. As relações entre suas concentrações na copa, altura total e incremento periódico anual, são positivas, mas não apresentam significância em relação ao incremento corrente anual.

Palavras-chave: Sítio, Nutrição, Análise foliar.

\footnotetext{
* Eng. Florestal, Prof. e Doutorando, Departamento de Ciências Florestais/CCR/UFSM. hoppe@ccr.ufsm.br

** Eng. Florestal, Doutorando em Eng. Florestal, Centro de Ciências Florestais e da Madeira/UFPR. Bolsista do CNPq. Rua Lothário Meissner, n. ${ }^{\circ}$ 3400, Jardim Botânico, Curitiba - PR, CEP 80210-170. caldeira@floresta.ufpr.br
} 


\section{Abstract}

The present research work was conducted in an even-aged forest of Araucaria angustifolia, with 29 years old, planted in the National Forest of Passo Fundo, RS (FLONA/Passo Fundo, RS). The objectives of this work were to analyze the concentration of crown's nutrients, and to correlate the growth parameters with nutrient's concentration in $A$. angustifolia leaves. In this study it was used two plots with 4,4 and 6,8 ha, respectively. In each point were selected four sites with different growth, based on plantation dominant high. By using average diameter of each site, it was selected four trees per site with similar high as the local dominant high. In the four selected trees, it was collected leaves of the last growth period for the nutritional analysis. The leaves were collected in each branch with north orientation. To perform the correlation of leaf nutrient's concentration, it was used the follow growth parameters: total height; annual periodic increment (API) in the last five years (API, 24-25) and the annual current increment (ACI) of the last year. The main concentration of $\mathrm{B}$ was observed in the upper branches and the highest concentrations of $\mathrm{Mg}$ and $\mathrm{Zn}$ were observed in the lower branches. It was observed that the increase of concentration of $\mathrm{Cu}$ and $\mathrm{B}$ in the leaves is associated to the biggest trees height. The best correlation are presented by concentrations of $\mathrm{Cu}$ and $\mathrm{B}$ in the leaves. The relation between these concentrations on the crown, total height and annual periodic increment are positive, but it shows no significance with relation to the annual current increment.

Keywords: Site, Nutrition, Foliage analysis.

\section{Introdução}

Segundo Reitz et al. (1983), a Araucaria angustifolia é uma árvore alta, de aspecto original e contrastante com as demais árvores do sul do Brasil, com 20 a $50 \mathrm{~m}$ de altura e 1 a $2 \mathrm{~m}$ de diâmetro à altura do peito. O tronco é perfeitamente cilíndrico, reto e raras vezes ramificado, em dois ou mais, casca grossa (até $15 \mathrm{~cm}$ ), resinosa, cuja superfície externa se desprende em placas, cinzento escuro.

A região de ocorrência natural da araucária fica de maneira geral entre os paralelos de $19^{\circ} 15^{\prime} \mathrm{e}$ $30^{\circ}$ de latitude Sul e entre os meridianos de $41^{\circ} 20^{\prime}$ e $54^{\circ}$ de longitude Oeste de Greenwich, indo desde o Estado de Minas Gerais até o Rio Grande do Sul. As maiores concentrações dessa espécie se encontram no Paraná, Santa Catarina e Rio Grande do Sul. O Estado de São Paulo possui uma área pequena com esta espécie, sendo que em Minas Gerais existiam apenas pequenos capões e árvores isoladas (MACHADO; SIQUEIRA, 1980). Golfari (1971) inclui também a província de Missiones na Argentina como área de ocorrência dessa espécie.

Conforme Carvalho (1994), no Brasil a área original com araucária era de aproximadamente de $200.000 \mathrm{~km}^{2}$, ocorrendo principalmente nos estados do Paraná, Santa Catarina, Rio Grande do Sul, com 40, 31, e 25\% de suas superfícies, respectivamente. Os demais 4\%, localizavam-se nos estados de São Paulo, Minas Gerais e Rio de Janeiro.

O crescimento inicial da araucária é lento, porém, a partir do terceiro ano, quando plantado em sítios adequados, apresenta taxas anuais de incrementos em altura entre 1 e $1,5 \mathrm{~m} \mathrm{e}$, a partir do sétimo ano, incrementos em diâmetro de 2 a 3 $\mathrm{cm}$. Dentro de um mesmo sítio, podem existir bons plantios em solos de mata, com incremento médio anual da ordem de $26 \mathrm{~m}^{3} \mathrm{ha}^{-1} \mathrm{ano}^{-1}$, e plantios ruins, em solos de campo, com $3 \mathrm{~m}^{3} \mathrm{ha}^{-1} \mathrm{ano}^{-1}$. Em solos de campo, o crescimento lento pode ser atribuído à deficiência de nutrientes e à pequena profundidade efetiva do solo (EMBRAPA, 1986).

Segundo Carvalho (1994), em alguns casos, a araucária pode atingir $30 \mathrm{~m}^{3} \mathrm{ha}^{-1} \mathrm{ano}^{-1}$, em condições ótimas de sítio. Em Colombo, PR, em sítios de fertilidade média e com alto teor de alumínio, a produtividade, dependendo da procedência utilizada, varia de 12 a $18 \mathrm{~m}^{3} \mathrm{ha}^{-1} \mathrm{ano}^{-1}$.

Apesar da excelente qualidade da madeira para diversos usos, sua importância socioeconômica e ecológica, e a grande potencialidade para a implantação de maciços florestais, a Araucaria angustifolia tem sido relegada a segundo plano nos projetos de reflorestamento. A baixa taxa de plantio é creditada, em parte, à exigência de sítios de boa qualidade pela espécie; à falta de conhecimento sobre procedências mais adequadas ao plantio em diferentes condições edafoclimáticas; à dificuldade de obtenção de sementes de algumas procedências testadas e aprovadas; à falta de sementes melhoradas geneticamente, de forma geral, à falta de conhecimentos de técnicas silviculturais e nutricionais, que pro- 
porcionem melhor relação produtividade/custo de produção; e principalmente ao menor crescimento volumétrico, quando comparado às espécies tradicionalmente plantadas dos gêneros Pinus e Eucalyptus.

Neste sentido, o trabalho teve como objetivo analisar os nutrientes na copa e correlacionar os parâmetros de crescimento, com a concentração de nutrientes nas folhas de Araucaria angustifolia, aos 29 anos de idade, plantadas na Floresta Nacional de Passo Fundo, RS.

\section{Materiais e métodos}

O presente estudo foi realizado em povoamentos plantados de Araucaria angustifolia aos 29 anos de idade, estabelecidos na Floresta Nacional de Passo Fundo, RS (FLONA/Passo Fundo). Foram utilizados materiais coletados nos talhões 53 e 54, cujas áreas são de 4,4 ha e 6,8 ha, respectivamente, plantados em 1948. A área da Floresta Nacional de Passo Fundo abrange 1.260 ha, sendo coberta por floresta nativa explorada e parte com plantios de Araucaria angustifolia e Pinus spp. A região de estudo situa-se no planalto médio do Estado do Rio Grande do Sul, com latitude de $28^{\circ}$
30'S e longitude de $52^{\circ} 20^{\prime} \mathrm{W}$ e uma altitude de 700 m s.n.m.

A Figura 1 mostra a localização dos talhões estudados dentro da Floresta Nacional de Passo Fundo, RS.

Segundo a classificação de Koeppen, o clima da região em estudo é subtropical do tipo Cfa, caracterizado por uma elevada umidade do ar, temperatura média anual inferior a $18^{\circ} \mathrm{C}$ e a precipitação em torno de $1.700 \mathrm{~mm}$, ocorrendo chuvas no inverno (MORENO, 1961).

De acordo com Lemos e Santos (1976), o relevo da região varia de suave a ondulado, ocasionando depressões fechadas. Nos talhões estudados, a declividade média encontra-se em torno de 10\%. O solo da área estudada pertence à Unidade de Mapeamento de Passo Fundo, ou seja, Latossolo Vermelho Distrófico Típico (EMBRAPA, 1999).

Para Andrae e Krapfenbauer (1976), grande parte dos solos da Floresta Nacional de Passo Fundo, RS, são vermelhos, profundamente decompostos, argilosos, geralmente de estrutura estável e bem drenados, muitas vezes caracterizados pela tendência de apresentarem um horizonte de iluviação de argila, o que pode ser, juntamente com o fator relevo, o causador da hidromorfia mais ou menos pronunciada.

FIGURA 1 - Localização dos talhões estudados dentro da área da Floresta Nacional de Passo Fundo, RS Figure 1 - Compartment Location in the area of Passo Fundo National Forest, RS

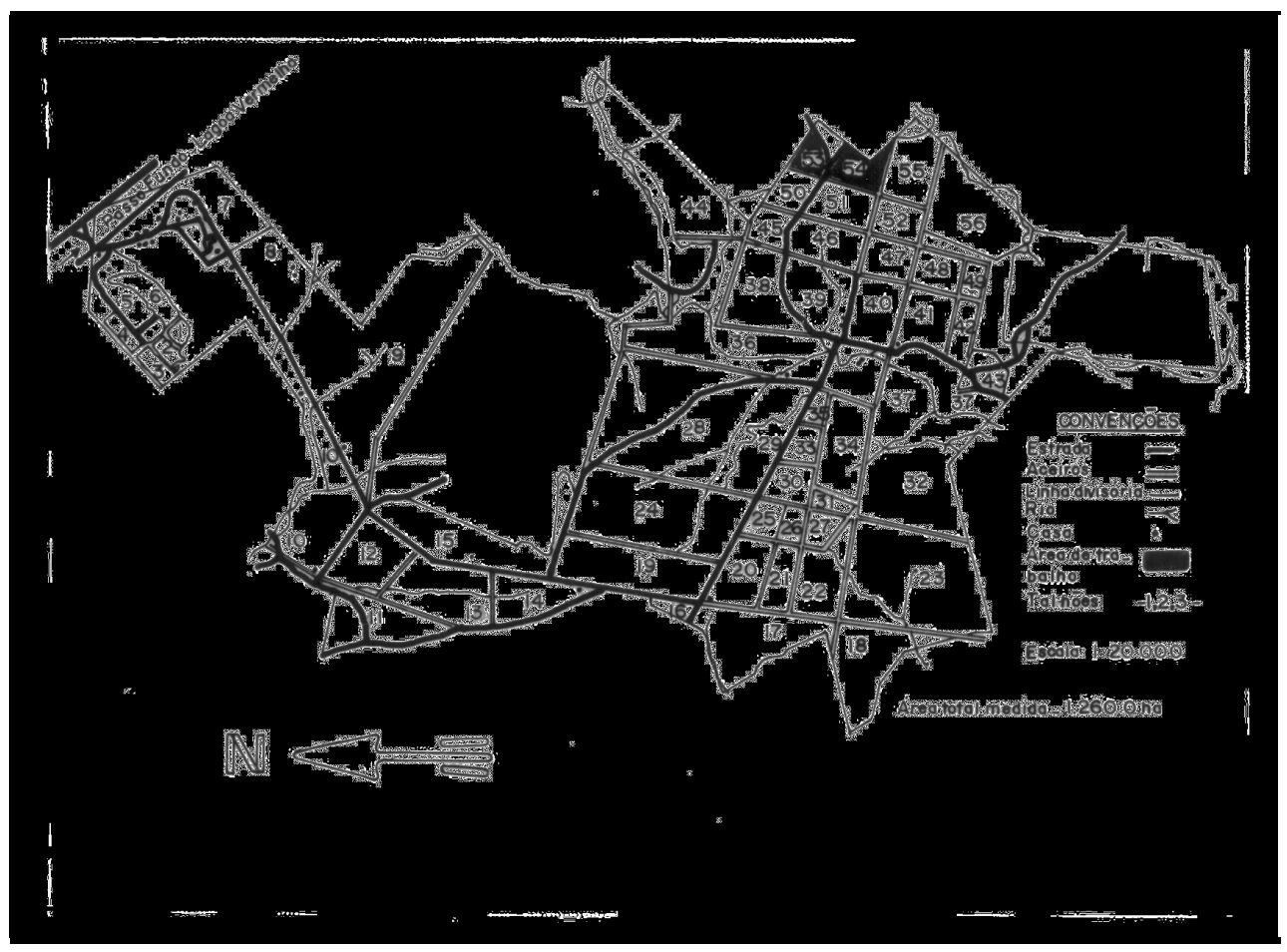


Na Tabela 1, consta as informações sobre os talhões 53 e 54.

TABELA 1 - Informações sobre os talhões, com Araucaria angustifólia, utilizados no presente estudo Table 1 - Information about plots with Araucaria angustifolia used in the present study

Tipo de Informação

\section{Talhões}

\begin{tabular}{ccc} 
& 53 & 54 \\
\cline { 2 - 3 } Área & 1948 & 1948 \\
Espaçamento & $4,4 \mathrm{ha}$ & $6,8 \mathrm{ha}$ \\
Replantios & $1,20 \mathrm{~m} \mathrm{x} 0,8 \mathrm{~m}$ & $1,20 \mathrm{~m} \times 0,4 \mathrm{~m}$ \\
Tratos culturais - capinas & 2 & 3 \\
Tratos culturais - roçadas & 3 capinas & 3 capinas \\
Raleamento & 5 roçadas & 6 roçadas \\
Desbaste seletivo & $2(1955-1959)$ & - \\
Produção total dos desbastes & $5(1961 / 62 / 64 / 70 / 71)$ & $4(1962 / 66 / 70 / 71)$ \\
Espaçamento atual aproximado & $206,7 \mathrm{~m}-$ & $390,6 \mathrm{~m} \_$ \\
Declividade & $3 \mathrm{~m} \mathrm{x} 3 \mathrm{~m}$ & $10 \%$ \\
\hline
\end{tabular}

Numa toposeqüência, abrangendo parte dos talhões 53 e 54, com 260 m de extensão, foram selecionados quatro sítios com crescimento diferente, baseando-se na altura dominante do povoamento. Em cada sítio foram demarcadas quatro parcelas de $100 \mathrm{~m}$, onde foram medidos todos os diâmetros à altura do peito (DAP) de cada parcela e calculado o diâmetro médio de cada sítio. Em seguida, foram selecionadas quatro árvores existentes em cada sítio, com diâmetros próximos do valor médio, obtendo-se, assim, quatro árvores com altura similar à altura dominante do local. estudo.

Na Figura 2, apresenta-se o esquema do relevo na toposeqüência, onde foi realizado o presente

FIGURA 2 - Representação esquemática do relevo e da altura dominante da Araucaria angustifolia nos diferentes sítios

Figure 2 - Representation (scheme) of relief and the dominant hights of Araucaria angustifolia in different sites

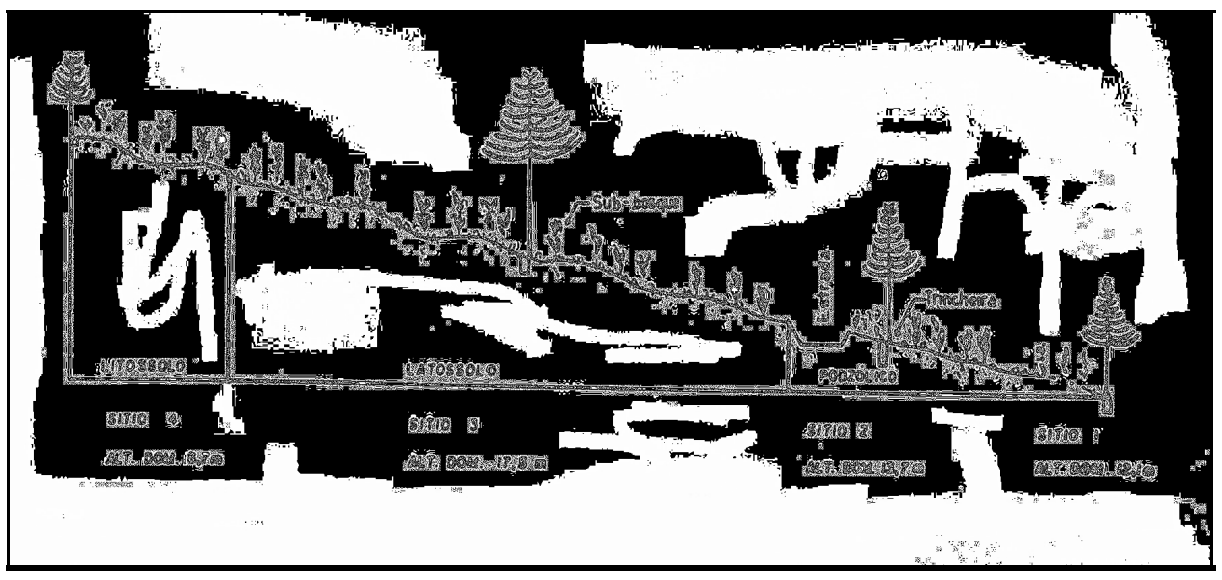


Nas quatro árvores selecionadas por sítio, em cada verticilo, situado na orientação norte, foram coletadas folhas do último período de crescimento para a análise química dos nutrientes. Estas foram acondicionadas em sacos plásticos e etiquetadas. As árvores selecionadas e abatidas foram secionadas a cada $2,0 \mathrm{~m}$, a partir do ápice até alcançar os últimos 10 anos de crescimento.

De acordo com as recomendações feitas por Reismann (1976), foi secionado o ramo, por meio de cortes transversais, eliminando, assim, todas as folhas que eventualmente não eram do período corrente de crescimento. Separados, os ramos foram colocados em bandejas esmaltadas e secos em estufa a $70^{\circ} \mathrm{C}$, durante oito horas para facilitar a separação das folhas. Em seguida, foram separadas 100 folhas, tomadas ao acaso, de cada amostra para determinar o seu peso. Posteriormente, as folhas sofreram uma segunda secagem a $105^{\circ} \mathrm{C}$, durante 24 horas, até seu peso constante, sendo moídas posteriormente para a determinação dos elementos químicos.

Baseando-se na metodologia descrita por Hildebrand (1976/1977), foram determinados Fe, Mn, Al, Zn, Cu e B. Por meio da espectrografia de absorção atômica, foram determinados o Fe, $\mathrm{Cu}, \mathrm{Mn}$ e $\mathrm{Zn}$ em chama de ar e acetileno. $\mathrm{O} \mathrm{Al}$ foi determinado por colorimetria, pelo método "Aluminon". O B foi determinado por colorimetria com Azometina-H (BASSON, 1969).

Os dados foram analisados mediante o cálculo de correlação simples, entre os valores de crescimento em altura e as características químicas das folhas. Esta análise de correlação simples visa a descobrir relações existentes entre o crescimento das árvores dominantes e cada uma das variáveis de sítio analisadas.

As correlações foram analisadas para o conjunto dos dados dos quatro sítios, havendo, assim, sempre dezesseis pares de observações no caso da correlação crescimento/análise foliar.
Foi utilizada a altura total $(\mathrm{H})$, o incremento periódico anual dos últimos cinco anos (IPA, 2429), o incremento corrente do último ano (ICA) e as concentrações de Fe, Mn, Al, Zn, Cu e B nas folhas.

Os valores sofreram uma transformação, segundo as recomendações de Freese (1967). Conforme o autor, a transformação dos dados em porcentagem, com valores abaixo de 20\%, é recomendável para uma melhor validade e confiança dos resultados. Esta transformação foi feita conforme seguinte fórmula:

$\mathrm{x}=\operatorname{arcsen} \sqrt{\mathrm{x}}$

Onde: $\mathrm{x}=$ valor transformado em porcentagem

A significância das correlações simples foi calculada para um nível de $95 \%$ de probabilidade, o que significa para 16 pares de dados, um valor de $r \geq 0,497$, e para correlações com 4 pares de dados, um valor de $r \leq 0,95$.

As correlações simples, entre os parâmetros de crescimento e os elementos químicos nas folhas, foram efetuadas com os valores do segundo, terceiro e quarto verticilos, separadamente, com os valores da média do segundo, terceiro e quarto verticilos, com a média do terceiro e quarto verticilos e com a média de todos os verticilos da mesma árvore.

\section{Resultados e discussão}

Os resultados da distribuição dos elementos químicos na copa de Araucaria angustifolia são apresentados e discutidos separadamente.

a) Ferro: O conteúdo desse elemento na copa, apresenta um comportamento análogo aos demais (Figura 3), com exceção do K, que se comporta de maneira inversa. Esta concentração nos verticilos inferior, talvez seja causada pela sua baixa mobilidade. 
FIGURA 3 - Distribuição de Fe na copa das árvores de Araucaria angustifolia em função do sítio (valores médios)

Figure 3 - Distribution of Fe on the tree's crown of Araucaria angustifolia as a function of the site (average values).

Em termos de valores médios na copa, Reissmann (1976), Dietrich (1977) e Blum (1977) encontraram valores semelhantes, em contrapartida, Van Goor (1965) obteve valores muito superiores aos encontrados neste trabalho (Tabela 2).

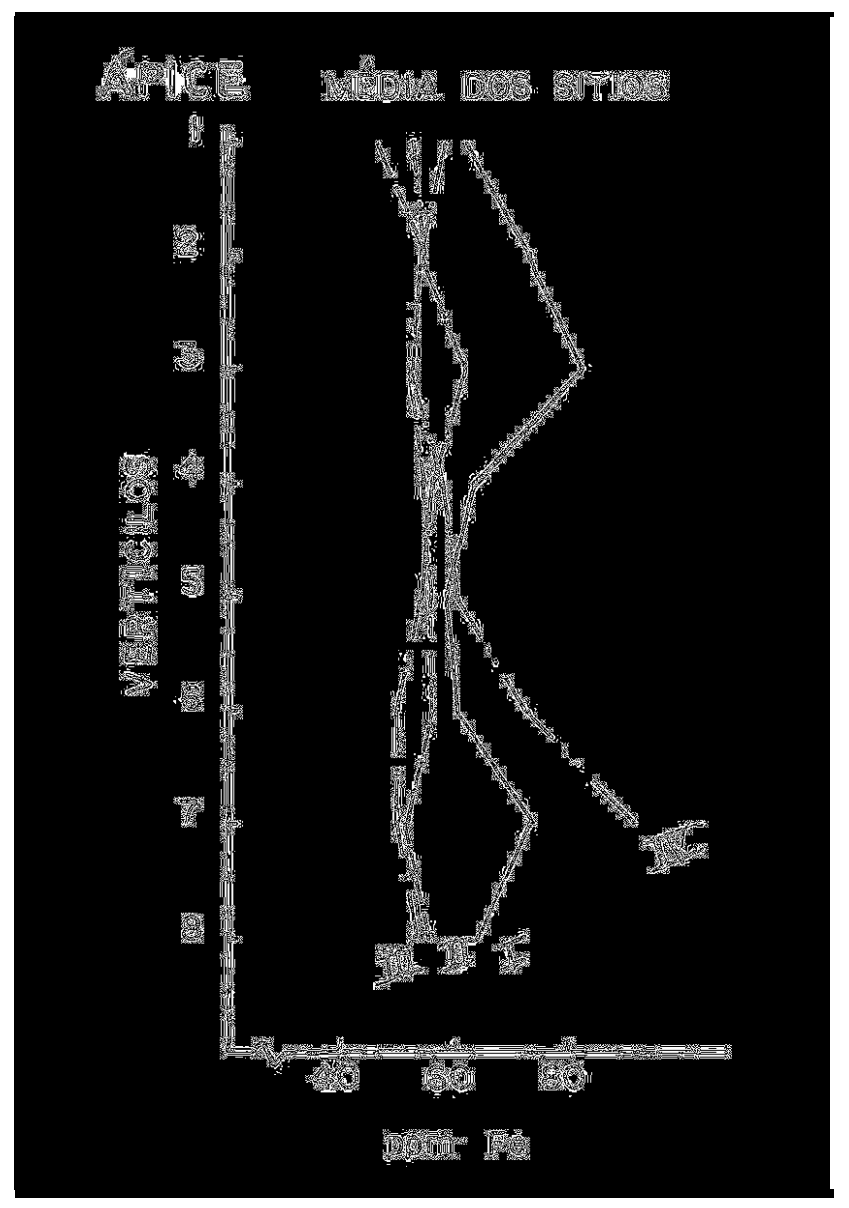

TABELA 2 - Comparação das concentrações dos nutrientes existentes nas folhas de Araucaria angustifolia entre o presente trabalho e os demais realizados com esta espécie (média dos verticilos)

Table 2 - Comparison of the nutrient's concentration in the leaf of Araucaria angustifolia between the present study and others realized with same specie (medium of the branches)

\begin{tabular}{cccccccccc}
\hline $\begin{array}{c}\text { Elementos } \\
\text { Ppm }\end{array}$ & \multicolumn{3}{c}{$\begin{array}{c}\text { Presente trabalho } \\
\text { Sítios (29 anos) }\end{array}$} & $\begin{array}{c}\text { BLUM } \\
(1977)^{*}\end{array}$ & $\begin{array}{c}\text { VAN GOOR } \\
(1969)\end{array}$ & $\begin{array}{c}\text { REISSMANN } \\
(1976)(2 \text { sítios })\end{array}$ & $\begin{array}{c}\text { DIETRICH } \\
(1976) \text { (4 sítios) }\end{array}$ \\
\cline { 2 - 10 } & 1 & 2 & 3 & 4 & & 25 anos & 18 anos 25 anos & 25 anos \\
\hline Fe & 68 & 71 & 55 & 51 & 50 & 103 & 67 & 47 & 52 \\
Mn & 440 & 470 & 340 & 570 & 300 & 283 & 249 & 987 & 750 \\
$\mathrm{Al}$ & 79,59 & 56,93 & 57,33 & 62,98 & - & - & - & - & 67,01 \\
$\mathrm{Zn}$ & 25,23 & 23,00 & 20,73 & 23,33 & 20 & - & - & - & 18,64 \\
$\mathrm{Cu}$ & 5,21 & 5,92 & 6,15 & 4,98 & 6 & - & - & - & 6,33 \\
$\mathrm{~B}$ & 18,67 & 19,52 & 20,71 & 14,68 & 20 & - & - & - & 11,50 \\
\hline
\end{tabular}

* Valores aproximados de 8 sítios no PR e SC (indicadores para um bom crescimento de Araucaria angustifolia 
b) Manganês: A distribuição do Mn na copa mostra-se com regularidade mais acentuada do que o Fe e apresenta uma concentração maior nos verticilos inferiores (Figura 4). No entanto, deve ser salientado o Sítio IV, onde a porcentagem de Mn atinge, na parte basal da copa, valores bem mais expressivos. Dietrich (1977) encontrou valores inversos, ou seja, concentrações maiores nos primeiros verticilos e, em termos de valores médios, há uma disparidade muito grande em relação aos demais trabalhos com esta espécie.

FIGURA 4 - Distribuição de Mn na copa das árvores de Araucaria angustifolia em função do sítio (valores médios)

Figure 4 - Distribution of Mn on tree's crown of Araucaria angustifolia in function of the site (medium values)

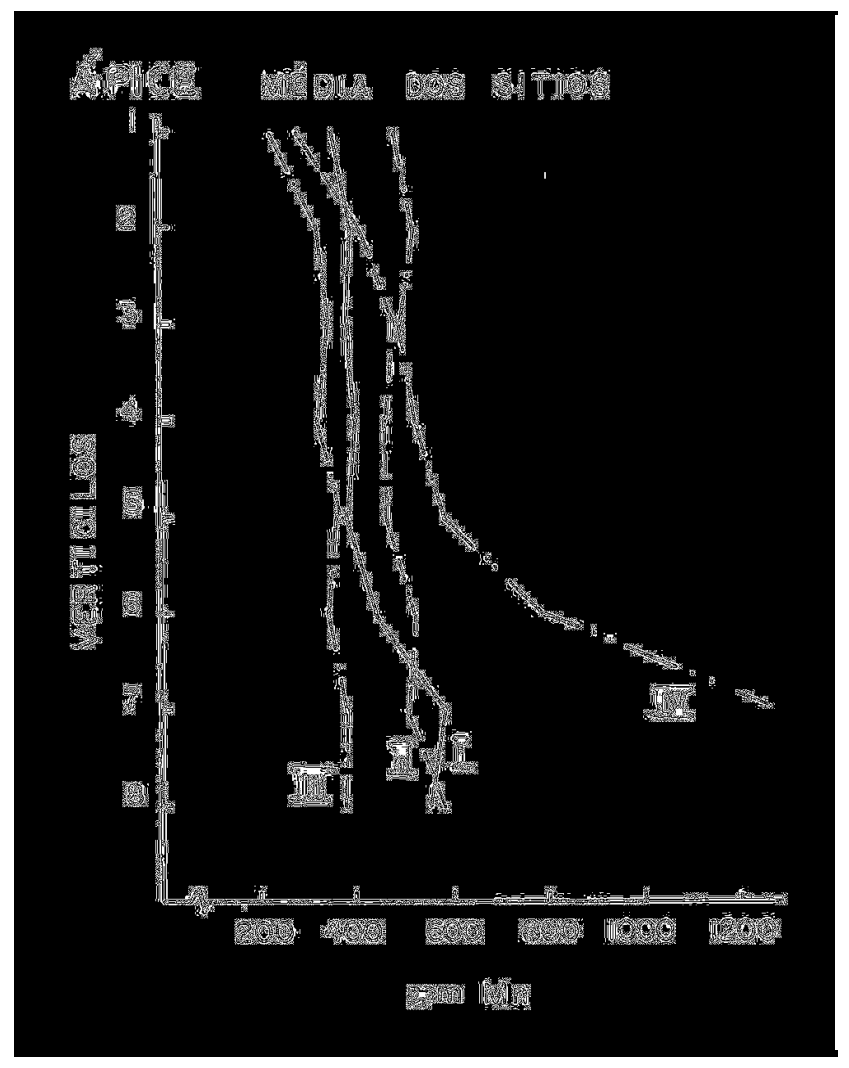

A baixa mobilidade basiletal do $\mathrm{Mn}$ pode apresentar uma distribuição regular, independente de ser a concentração maior no ápice ou na base da copa Mengel (1972).

c) Alumínio: As concentrações deste elemento são maiores nos verticilos inferiores
(Figura 5), devido sua baixa mobilidade. $\mathrm{O}$ interesse de analisar o Al nas folhas ocorre pelo fato desse elemento, quando livre no solo, fixar íons como P, e, como conseqüência, o crescimento poderá ser prejudicado, não pela falta dos elementos no solo, mas pela fixação destes pelo alumínio, além de influenciar na acidez do solo.

FIGURA 5 - Distribuição de Al na copa das árvores de Araucaria angustifolia em função do sítio (valores médios)

Figure 5 - Distribution of Al on tree's crown of Araucaria angustifolia in function of the site (medium values)

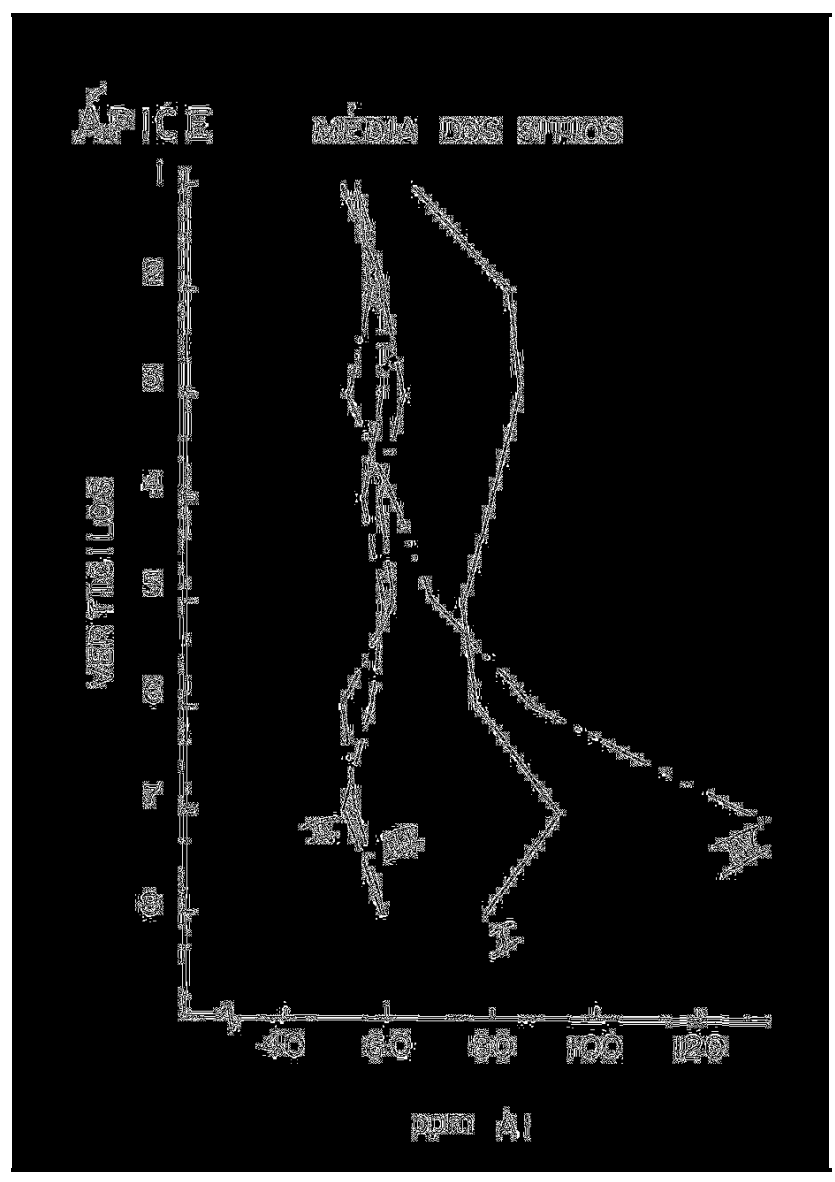

Em termos comparativos, Dietrich (1977) encontrou valores semelhantes em seu trabalho, realizado em Três Barras, SC (Tabela 2). A presença de Al nos verticilos da copa ocorre porque a planta não apresenta habilidade de selecionar o elemento para a absorção.

d) Zinco: Com relação ao Zn, foi cons- 
tada uma variação na sua distribuição na copa, dentro de cada sítio estudado. Foi observado, no entanto, um padrão regular nas concentrações ao longo da copa, quando observados os valores médios (Figura 6). Dietrich (1977), em seu estudo, encontrou uma maior concentração nos verticilos superiores. E, em termos médios na copa, o presente trabalho apresenta valores superiores, estando, também, acima do valor recomendado por Blum (1977), para um bom crescimento desta espécie (Tabela 2).

FIGURA 6 - Distribuição de Zn na copa das árvores de Araucaria angustifolia em função do sítio (valores médios)

Figure 6 - Distribution of Zn on tree's crown of Araucaria angustifolia as a function of the site (average values)

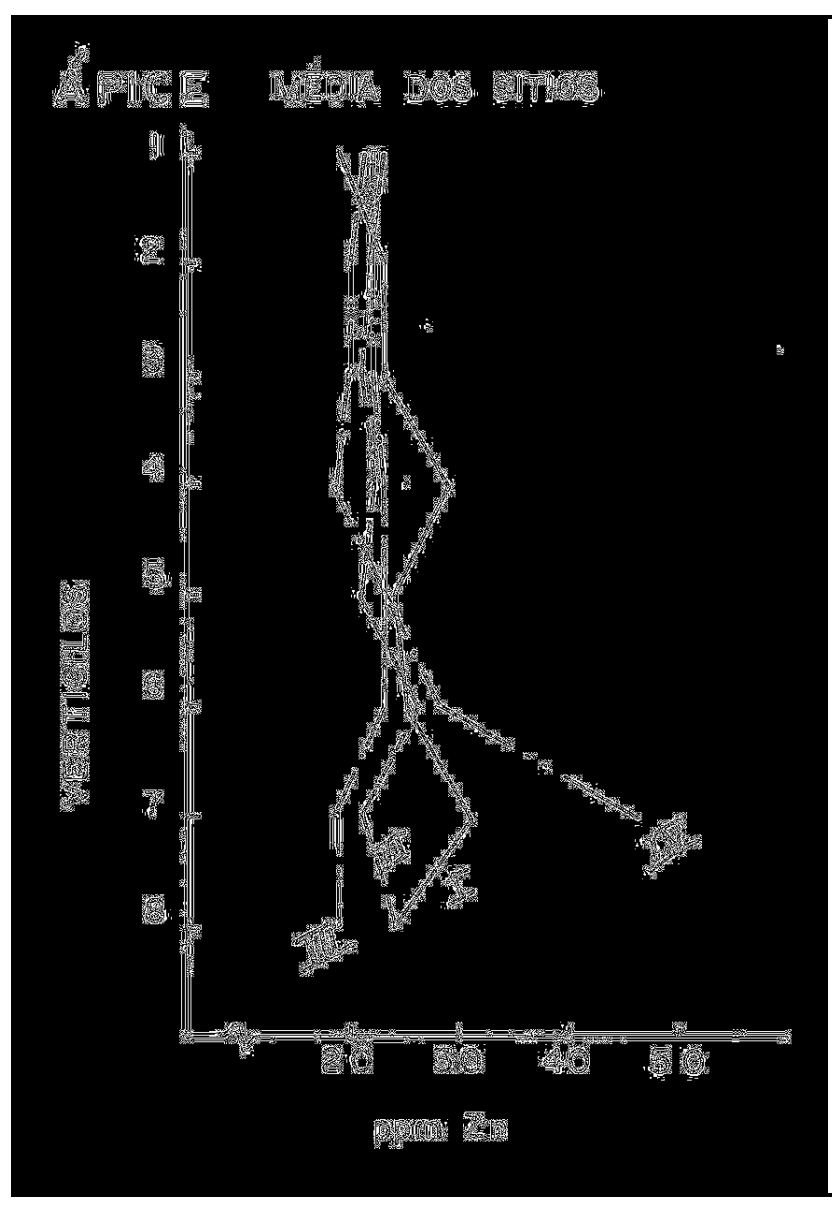

Esta discrepância de valores pode ser atribuída às condições fisiológicas da árvore; pode-se pensar, também, que pelo fato das árvores encontrarem-se em franco desenvol- vimento, causa atribuída a efeitos dos desbastes, uma maior quantidade de $\mathrm{Zn}$ foi absorvida, por este elemento de importância para as atividades enzimáticas. Também, pode-se atribuir a maior concentração de $\mathrm{Zn}$ na copa à origem do solo, uma vez que o basalto possui na sua constituição, boa quantidade de $\mathrm{Zn}$.

e) Cobre: Não há possibilidade de definir qual o verticilo que apresenta maior concentração de $\mathrm{Cu}$, devido 'a pouca variação na concentração deste elemento ao longo da copa, quer se considere o sítio individualmente, quer se observe a média dos quatro sítios (Figura 7).

FIGURA 7 - Distribuição de Cu na copa das árvores de Araucaria angustifolia em função do sítio (valores médios)

Figure 7 - Distribution of Cu on tree's crown of Araucaria angustifolia as a function of the site (average values)

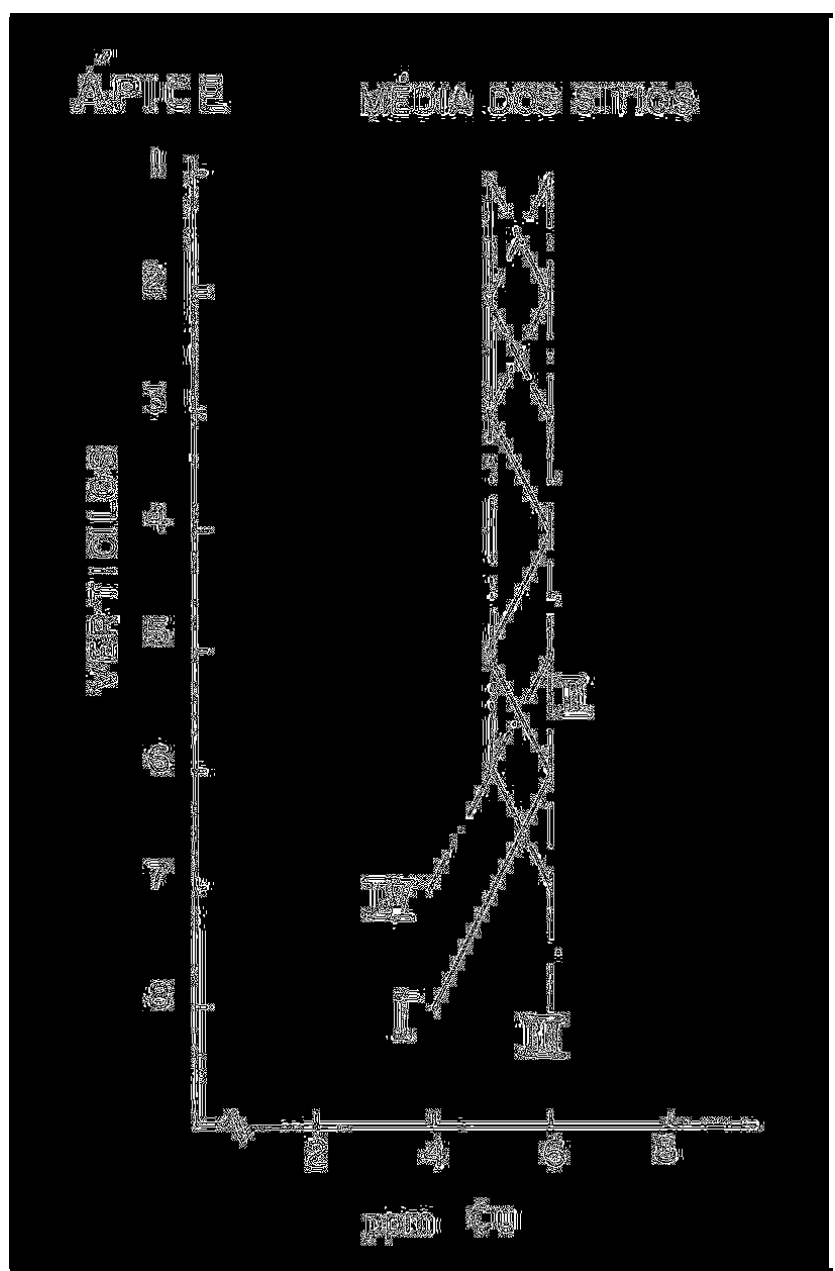


f) Boro: A distribuição do B, na copa das árvores estudadas, apresenta-se com maior concentração no ápice (Figura 8). O mesmo comportamento foi observado por Dietrich (1977), em seu estudo, realizado com a mesma espécie, em Três Barras, SC.
Em termos de valores médios na copa das árvores estudadas, as concentrações de B podem ser consideradas relativamente iguais aos valores indicados por Blum (1977), com exceção do Sítio IV, que mostra um valor inferior aos demais.

FIGURA 8 - Distribuição de B na copa das árvores de Araucaria angustifolia em função do sítio (valores médios)

Figure 8 - Distribution of B on tree's crown of Araucaria angustifolia in function of the site (average values)

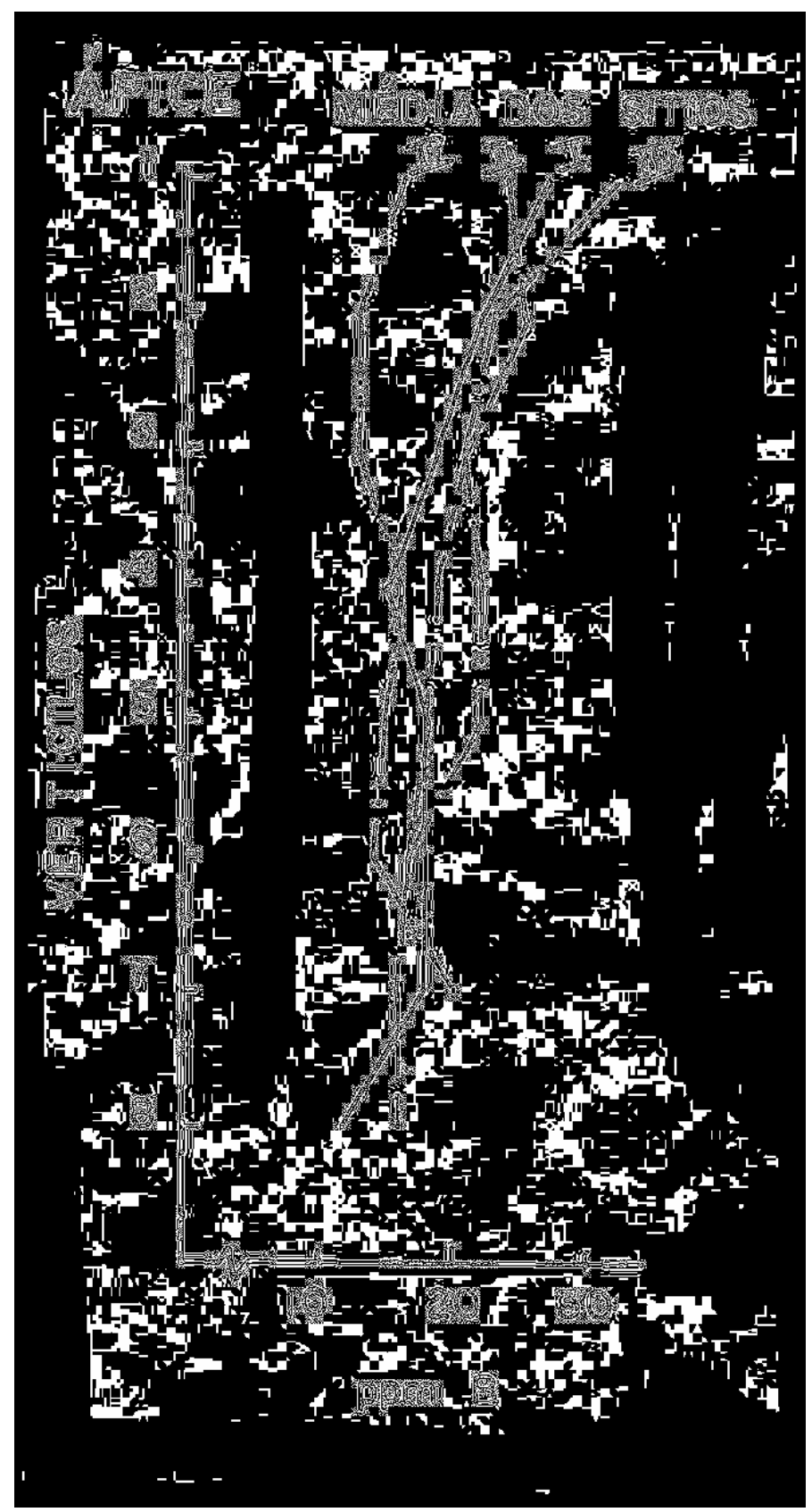


As correlações entre o nível nutricional das árvores, representado pela análise química das folhas e o crescimento, representado pela altura total $(\mathrm{H})$, incremento periódico anual dos últimos cinco anos (IPA 24-29) e o incremento corrente do último ano (ICA), podem ser vistas nas Tabelas 3, 4 e 5 , respectivamente.

As melhores correlações são apresentadas pelos percentuais de $\mathrm{Cu}$ e B. Para ambos, as relações entre suas concentrações na copa, altura total e incremento periódico anual são positivas, porém, não tendo significância em relação ao incremento corrente anual.

Com exceção do $2 .^{\circ}$ verticilo, o elemento $\mathrm{Cu}$ mostrou correlação positiva com $\mathrm{H}$ nos demais, bem como nas suas médias consideradas (Tabela 3). Também, este elemento mostrou correlações entre seus conteúdos na copa e o IPA, com exceção do $2 .^{\circ}$ e a média dos $3 .^{\circ}$ e $4 .^{\circ}$ verticilos.

TABELA 3 - Coeficientes de correlação simples entre o conteúdo de elementos nas folhas e a altura total Table 3 -Coefficient of correlation between the nutrient's concentration in the leaf of A. Angustifolia and the total height

\begin{tabular}{ccccccc}
\hline Verticilo & $\mathrm{Fe}$ & $\mathrm{Mn}$ & $\mathrm{Zn}$ & $\mathrm{Al}$ & $\mathrm{Cu}$ & $\mathrm{B}$ \\
\hline 2 & 0,014 & $-0,378$ & $-0,017$ & $-0,016$ & 0,411 & 0,425 \\
3 & 0,070 & $-0,404$ & $-0,213$ & 0,107 & 0,599 & 0,510 \\
4 & $-0,212$ & $-0,478$ & $-0,216$ & $-0,175$ & 0,678 & 0,509 \\
$\mathrm{M}_{2+3+4}$ & $-0,000$ & $-0,017$ & $-0,128$ & $-0,013$ & 0,559 & 0,526 \\
$\mathrm{M}_{3+4}$ & $-0,014$ & $-0,414$ & $-0,031$ & $-0,258$ & 0,728 & 0,533 \\
$\mathrm{MT}$ & $-0,262$ & $-0,505$ & $-0,294$ & $-0,395$ & 0,655 & 0,451 \\
\hline
\end{tabular}

$\mathrm{M}$ = média; $\mathrm{MT}$ = média total.

Entre os demais micronutrientes, o Fe apresentou uma correlação negativa, estatisticamente significante, apenas para a relação entre a média da sua concentração nos $2 .^{\circ}, 3 .^{\circ}$ e $4 .^{\circ}$ verticilos, mas o IPA não mostrou correlação com os demais parâmetros de crescimento.

A relação do Mn com o crescimento foi significativa apenas para sua concentração média na copa e, para a H, esta correlação foi negativa.
As concentrações de $\mathrm{Zn}$ e $\mathrm{Al}$ nas folhas não se correlacionaram com os parâmetros de crescimento considerados.

Sintetizando, o acima exposto, e observando as Tabelas 3, 4 e 5 de maneira conjunta, deve ser salientado alguns pontos importantes na seleção dos parâmetros a serem usados no estudo das relações sítio/crescimento.

TABELA 4 - Coeficientes de correlação simples entre o conteúdo de elementos nas folhas e o IPA (24 - 29 anos) Table 4 - Coefficient of correlation between the nutrient's concentration in the leaf of $A$. angustifolia and the AIP (24-29 years old)

\begin{tabular}{ccccccc}
\hline Verticilo & $\mathrm{Fe}$ & $\mathrm{Mn}$ & $\mathrm{Zn}$ & $\mathrm{Al}$ & $\mathrm{Cu}$ & $\mathrm{B}$ \\
\hline 2 & 0,182 & $-0,349$ & 0,148 & 0,152 & 0,157 & 0,467 \\
3 & $-0,067$ & $-0,234$ & $-0,123$ & $-0,001$ & $-0,782$ & 0,507 \\
4 & $-0,400$ & $-0,305$ & $-0,134$ & $-0,180$ & 0,780 & 0,539 \\
$\mathrm{M}_{2+3+4}$ & $-0,593$ & $-0,146$ & 0,346 & $-0,010$ & 0,639 & 0,554 \\
$\mathrm{M}_{3+4}$ & $-0,167$ & $-0,269$ & $-0,108$ & $-0,005$ & 0,193 & 0,511 \\
MT & $-0,268$ & $-0,421$ & $-0,135$ & $-0,387$ & 0,622 & 0,442 \\
\hline
\end{tabular}

M = média; $\mathrm{MT}$ = média total. 
Nas Tabelas 3 e 4, observa-se que as melhores correlações ocorreram com as concentrações dos elementos existentes no $3 .^{\circ}$ e $4 .^{\circ}$ verticilos, ou com a média dos mesmos.

Embora não se tenha feito estudos separados por sítio, o incremento e a composição des- te, entre os sítios e dentro de cada sítio, tem uma grande variação, principalmente no crescimento do último ano. Observa-se que os elementos Cu e $\mathrm{B}$ foram os únicos que mostraram uma correlação positiva com o crescimento das árvores.

TABELA 5 - Coeficientes de correlação simples entre o conteúdo de elementos nas folhas e o ICA Table 5 - Coefficient of correlation between the nutrient's concentration in the leaf of $A$. angustifolia and the AIC

\begin{tabular}{ccccccc}
\hline Verticilo & $\mathrm{Fe}$ & $\mathrm{Mn}$ & $\mathrm{Zn}$ & $\mathrm{Al}$ & $\mathrm{Cu}$ & $\mathrm{B}$ \\
\hline 2 & $-0,328$ & $-0,108$ & 0,138 & $-0,277$ & 0,096 & 0,000 \\
3 & $-0,297$ & $-0,243$ & 0,128 & $-0,495$ & 0,347 & 0,083 \\
4 & $-0,093$ & $-0,171$ & 0,125 & 0,044 & 0,069 & 0,074 \\
$\mathrm{M}_{2+3+4}$ & $-0,294$ & $-0,196$ & 0,073 & $-0,170$ & $-0,260$ & 0,018 \\
$\mathrm{M}_{3+4}$ & $-0,227$ & $-0,122$ & $-0,060$ & 0,131 & 0,200 & 0,032 \\
$\mathrm{MT}$ & $-0,142$ & $-0,257$ & $-0,159$ & $-0,105$ & $-0,001$ & $-0,034$ \\
\hline
\end{tabular}

$\mathrm{M}$ = média; $\mathrm{MT}$ = média total.

\section{Conclusões}

- As maiores concentrações de B foram observadas nos verticilos superiores, porém, Mn e Zn, nos verticilos inferiores e as concentrações dos demais nutrientes foram variáveis, ou seja, sem uma tendência marcante e uniforme nos quatro sítios.

- Não foi observado uma variação nítida no que se refere às concentrações dos nutrientes nas folhas de Araucaria angustifolia, entre os sítios com maior e menor crescimento, pois as concentrações encontradas podem ser enquadradas dentro de uma faixa de bom crescimento.

- O aumento nas concentrações de $\mathrm{Cu}$ e B, nas folhas de Araucaria angustifólia, está associado às maiores alturas das árvores. Contudo, cabe ressaltar que os ICA e o IPA estão mais relacionados ao estado nutricional dos anos anteriores.

- As melhores correlações são aquelas apresentadas pelas concentrações de $\mathrm{Cu}$ e $\mathrm{B}$ nas folhas de Araucaria angustifolia. Para ambos os nutrientes, as relações entre suas con- centrações na copa, altura total e IPA, foram positivas.

\section{Referências}

ANDRAE, F.H.; KRAPFENBAUER, A. Inventário de Araucaria angustifolia: biomassa e nutrientes. UFSM: Santa Maria 77p. 1976.

BASSON, W. D. Na automated procedure for the determination of Baron In: Plant tissue analyst. n.94, 1135-1141p. 1969.

BLUM, W. E. H. Araucária: o seu futuro não está perdido. In: BRASIL MADEIRA, p.10-12, 1977.

CARVALHO, P. E. R. Espécies florestais brasileiras: recomendações silviculturais, potencialidades e uso da madeira. Colombo: EMBRAPACNPF; Brasília: EMBRAPA-SPI, 1994. p.70-78.

DIETRICH, A. B. Relações entre dados analíticos do solo, análise foliar e dados de crescimento de Araucaria angustifolia (Bert.) O. Ktze. Universidade Federal de Viçosa, Viçosa: UFV, 1977. Tese (Doutorado em Ciências Florestais) Universidade Federal de Viçosa, 1977.

EMBRAPA - Empresa Brasileira de Pesquisa Agropecuária. Sistema brasileiro de classifica- 
ção levantamento de solos: EMBRAPA/SNPS. Rio de Janeiro, 1999. 412p.

EMBRAPA - Empresa Brasileira de Pesquisa Agropecuária. Zoneamento ecológico para plantios florestais no Estado do Paraná. Brasília: EMBRAPA, 1986. 89p. (EMBRAPA - CNPF. Documentos, 17).

FREESE, F. Elementary Statistical Methods for Forester's. Agriculture Handbook 317 U.S. Department of Agriculture. 1967.

HILDEBRAND, C. et al. Manual de análise química de solos e plantas. Universidade Federal do Paraná. Setor de Ciências Agrárias. Curitiba. PR. 255p. 1976/1977.

LEMOS, R.C., SANTOS, R.D. Manual de métodos de trabalho de campo. Sociedade Brasileira de Ciência do Solo. Comissão de Métodos de Trabalho de Campo. Campinas. SP. 1976.

MENGEL, I. K. Ferntransport, Stoffbeweglichkeit und Blattdüngung um Ernahrung um Stoffwechsel
Verlag 1972. Cap Stuttgart, Gustav Fischer Verlag, 2: 243-257.

MOREnO, J. A. Clima do Rio Grande do Sul. Porto Alegre: Secretaria da Agricultura, 1961. 42p.

REISSMANN, C. B. Variação anual dos nutrientes em Araucaria angustifolia (Bert.) O. Ktze., em função da época de amostragem. Curitiba: UFPR, 1976. 86p. Dissertação (Mestrado em Ciências Florestais) - Universidade Federal do Paraná, 1976.

VAN GOOR, C. P. Reflorestamento com coníferas no Brasil: aspectos ecológicos dos plantios da região sul, particularmente com Pinus elliottii e Arancaria angustifolia. Rio de Janeiro. Serviço Florestal do Ministério da Agricultura. Setor de Inventários Florestais. Boletim n. 9. 1965. 